
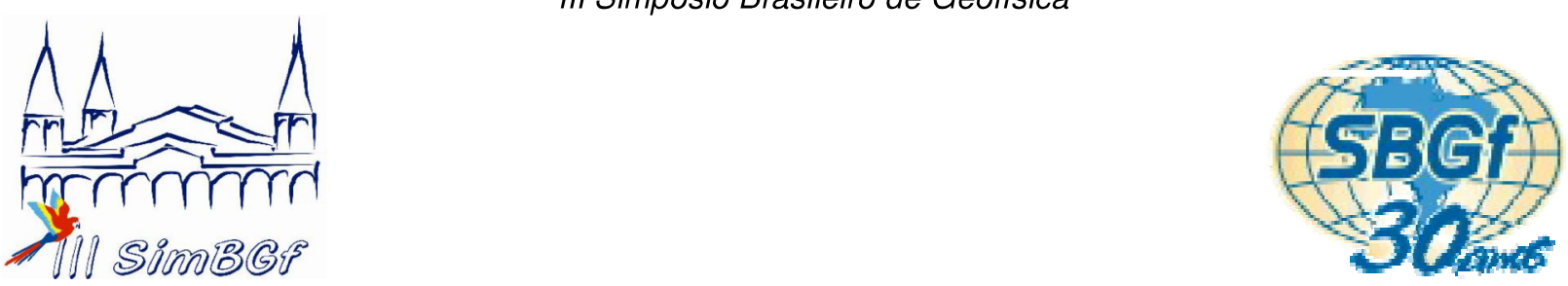

\title{
Mapeamento de Interferências com GPR: Uma aplicação na Mina Fazenda Brasileiro, Teofilândia, BA
}

Leonardo A. O. Mendes*, Jacira C. B. Freitas, Marco Antônio B. Botelho - Universidade Federal da Bahia, CPGG

Copyright 2008, SBGf - Sociedade Brasileira de Geofísica

Este texto foi preparado para a apresentação no III Simpósio Brasileiro de Geofísica, Belém, 26 a 28 de novembro de 2008. Seu conteúdo foi revisado pelo Comitê Técnico do III SimBGt, mas não necessariamente representa a opinião da SBGf ou de seus associados. E proibida a reprodução total ou parcial deste material para propósitos comerciais sem prévia autorização da SBGt.

\section{Resumo}

Empregamos o método GPR (Ground Penetrating Radar) ou Radar de Penetração no Solo na detecção de tubulações enterradas, considerando a resolução que o método possui, particularmente em profundidades rasas como as do sítio estudado (entre 0,2 e $2,0 \mathrm{~m}$ ). O método foi aplicado numa antiga planta de lixiviação da Mina Fazenda Brasileiro, Teofilândia, BA. O GPR empregou uma antena de $200 \mathrm{MHz}$, com a qual revelou tubulações com diferentes diâmetros, variando de canos com 3,5 a $12 \mathrm{~cm}$. A técnica GPR permitiu detectar tubulações de diferentes materiais, sejam plásticos e PVCs até tubulações metálicas.

\section{Introdução}

Localizada no município de Teofilândia a nordeste do estado da Bahia, a Mina Fazenda Brasileiro abriga uma das maiores jazidas de ouro do Brasil iniciando suas atividades há mais de 20 anos sendo operada inicialmente pela companhia Vale do Rio Doce até meados de 2003, quando foi adquirida pela mineradora canadense Yamana.

Visando melhores resultados no beneficiamento do minério aurífero e maior produtividade, a antiga usina de lixiviação foi desativada restando na área toda a sua estrutura física e a rede de tubulações que conectavam a usina a dois reservatórios destinados ao tratamento do minério. É nesta área onde, objetivando a identificação de algumas destas tubulações, o presente trabalho se desenvolveu.

Para tanto utilizamos o método GPR já largamente empregado em investigações de objetos enterrados como, tubos, dutos, cabos entre outros, e com eficácia comprovada nesta área de aplicação. Diversos trabalhos demonstram as vantagens que o método possui, apresentando uma relação custo/benefício baixa aliada à rapidez na execução.

O GPR é um método geofísico não-invasivo, daí sua grande utilização em locais onde há construções e instalações de infra-estrutura, como em áreas urbanas, assim como no presente estudo. O método é baseado na propagação de ondas eletromagnéticas de alta freqüência $(10 \mathrm{MHz}$ a $1 \mathrm{GHz})$ emitidos por uma antena transmissora. A propagação do sinal do radar em subsuperfície além de ser controlada pela freqüência do sinal transmitido depende das propriedades elétricas do solo, principalmente da condutividade elétrica e da permissividade dielétrica. À medida que o sinal percorre o interior da Terra vai rastreando os diferentes materiais existentes e sendo afetado pelas mudanças nas propriedades elétricas desses materiais em subsuperfície. É justamente esse contraste das propriedades elétricas dos materiais que causa a reflexão de parte do sinal que retorna à superfície sendo então captado pela antena receptora posicionada na superfície do terreno (Davis \& Annan, 1989).

O aumento da condutividade elétrica de solos e rochas introduz perdas significativas na propagação do sinal, cujo resultado é a limitada profundidade de penetração (Beres \& Haeni, 1991). Apesar do terreno onde foi realizado o levantamento ser constituído por um solo argiloso, bastante condutivo e, portanto prejudicial ao GPR, obtivemos uma boa resposta do sinal do radar, pois além dos alvos do estudo se encontrarem a uma profundidade rasa, o contraste entre os materiais é consistente (tubos de PVC ou metálicos e o solo argiloso), conseguindo uma boa resolução do sinal do radar.

\section{Metodologia}

O trabalho realizado consistiu na aquisição $e$ interpretação de dados de radar na área da antiga planta de lixiviação da mina (Figura 1) visando a identificação de tubulações. Ao todo, foram realizados sete perfis com o radar em pistas de acesso laterais a usina e a dois reservatórios que integram a planta. As disposições espaciais dos perfis estão ilustradas nas figuras que contém imagens da área. Cada perfil foi registrado seguindo uma configuração designada por perfil contínuo ou seção de afastamento constante.

Neste artigo, são apresentados quatro perfis de radar (Perfis 1, 2, 3, e 4), que apresentam escavações realizadas segundo as indicações de anomalias constatadas nos perfis confirmando as tubulações existentes no local da linha de aquisição. As escavações ficaram a cargo da mineradora, e até o término deste trabalho apenas estas que apresentamos tinham sido executadas. 


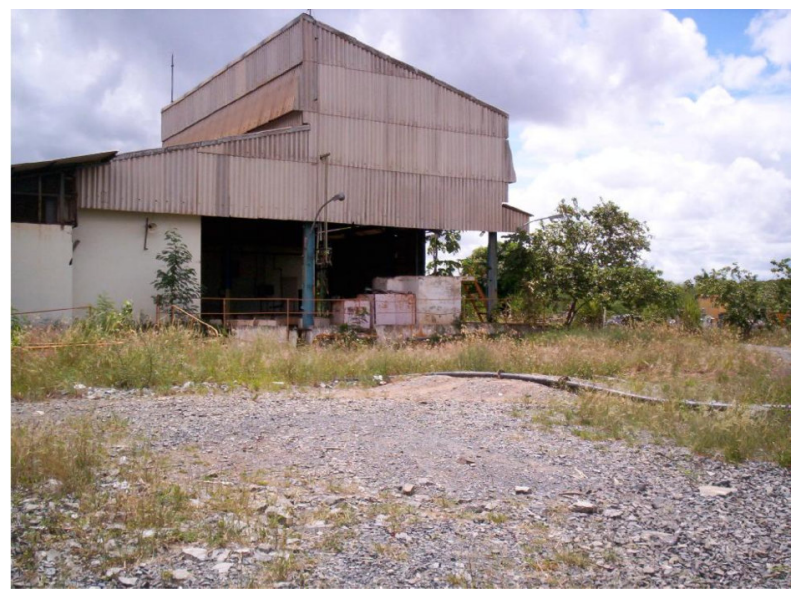

Figura 1 - Vista lateral da antiga usina de lixiviação.

O modelo de GPR utilizado é um SIR SYSTEM 2000 fabricado pela GSSI, com antenas de freqüência central de $200 \mathrm{MHz}$ suficiente para alcançar os alvos determinados mesmo sendo o local constituído de material argiloso.

O processamento dos dados foi realizado utilizando-se 0 software RADAM 6.5 (GSSI, 2005) com as imagens da subsuperfície sendo reveladas através de radargramas no formato Linescan. A rotina adotada para esta etapa foi a correção do tempo zero, ganho exponencial, filtragem passa-banda, conversão tempo-profundidade.

\section{Resultados}

O primeiro perfil de radar foi realizado em uma pista de acesso lateral a usina tendo como referência para o ponto de partida a pedra indicada pela seta amarela e como ponto de chegada a cerca com tela de arame ao final da linha de aquisição, vide Figura 2. O radargrama (Figura 3) nos permite observar nos intervalos entre 6 a $13 \mathrm{~m}$ e 25 a $28 \mathrm{~m}$ zonas de atenuação de radar que podem estar associadas à mudança de material para mais argiloso, ou zonas saturadas por água ou ainda contendo substâncias muito condutivas, como por exemplo, derrames de ácidos. No ponto 1 (15.0 e $15.5 \mathrm{~m}$ ) cruzamos duas tubulações, com a primeira aflorante (vide Figuras 1 e 2), ambas a uma profundidade de $0.20 \mathrm{~m}$. Os tubos posicionados a 19.0 e $19.5 \mathrm{~m}$ do início do perfil, à mesma profundidade, podem ser vistos na Figura 4, após as escavações, confirmando os dados. A anomalia indicada no ponto 3 à distância de $24.00 \mathrm{~m}$ e uma profundidade estimada de $0.30 \mathrm{~m}$, está associada a uma tubulação que pode ser vista na Figura 5. No ponto 20 pequeno refletor pode ser interpretado como um cabo enterrado. Por último, ao final do perfil, no ponto 4 , à profundidade aproximada de $0.20 \mathrm{~m}$ constata-se a presença de mais uma anomalia associada a um tubo visível após a escavação e indicado na Figura 6. Nesta Figura, o ponto 2 refere-se ao perfil 2 que será mostrado a seguir, mas a título de comparação este ponto 2 corresponde ao ponto 4 do perfil 1 .

O perfil de retorno do levantamento anterior é apresentado no radargrama da Figura 7, tendo início da linha de aquisição do perfil a cerca com tela de arame ao fundo da Figura 2 e o seu fim na seta amarela indicada na mesma Figura. Nele podemos verificar que os pontos indicados como 3 e 4 representam respectivamente os pontos 1 e 3 da Figura 3 . Este segundo perfil, mostrou nos pontos 1 e 2 interferências associadas a duas tubulações existentes e vistas na imagem da Figura 8 feita após a escavação. No primeiro ponto o tubo está próximo à posição inicial de funcionamento da antena do radar e no segundo ponto o tubo está a uma distância de $1.5 \mathrm{~m}$ do início do perfil, ambos a uma profundidade estimada de $0.30 \mathrm{~m}$. Esta seção apresentou um resultado com menor contraste de amplitude do sinal de radar do que a seção anterior.

As duas próximas seções realizadas entre os dois reservatórios tiveram os seus pontos de partida e de chegada com orientações inversas, mas próximos, como mostra a Figura 8. As Figuras 9 e 10 correspondem respectivamente os perfis de ida e volta. Comparando-os podemos constatar a coerência de algumas anomalias registradas, destacando-se os pontos 2 e 3 do perfil 4 e indicados na Figura 9 tendo como anomalias correspondentes no perfil 5 os pontos 2 e 1 (Figura 10), que são interpretados como interferências devido à existência de tubos. Tendo sido constatada uma tubulação realizada a escavação correspondendo nos dois perfis ao ponto 2 (Figura 11). Também houve concordância nas duas interferências identificadas no ponto 1 do perfil 4 (ponto 3 do perfil 5), podendo ser interpretados também como tubulações. Já o ponto 4 do perfil 4 apresenta uma reflexão que pode estar associada a um corpo enterrado estando a profundidade de $0.60 \mathrm{~m}$. No perfil 5 também foi possível identificar mais uma anomalia indicada no ponto 4 , avaliada em $0.50 \mathrm{~m}$ de profundidade, assim como, duas zonas de atenuação de radar, nos intervalos de 0 a $6.5 \mathrm{~m}$ e 15.5 e $25.0 \mathrm{~m}$ ambas entre 0.45 e $1.20 \mathrm{~m}$ de profundidade, resultantes, possivelmente, dos mesmos fenômenos citados para as atenuações do perfil 1. Nos dois perfis observa-se ainda a existência de uma mesma zona de atenuação no início da seção para o perfil 4 e ao final para o perfil 5.

\section{Discussão e Conclusões}

Pelos resultados apresentados neste trabalho podemos confirmar a capacidade que o método geofísico GPR tem na investigação de tubulações rasas mesmo em terrenos constituídos por materiais com alta condutividade como neste caso. Sua versatilidade em campo, aliada à fácil aplicabilidade, quando comparado a outros métodos geofísicos, o tornam uma ferramenta poderosa no imageamento da subsuperfície.

Em todas as seções adquiridas na área da usina foi possível identificar interferências que podem ser associadas à presença de tubulações, tendo sido comprovadas nos casos onde foram realizadas escavações. Também foi possível definir intervalos 
anômalos (zonas de atenuação) e seus limites, caracterizados por elevada condutividade elétrica em relação ao meio em redor, resultando na atenuação da onda de radar.

O aumento de condutividade elétrica pode indicar que ocorreu no local do levantamento mudança de material para mais argiloso, ou zonas com saturação em água ou ainda a presença de alguma substância mais condutiva, como ácido.

Para as interferências causadas por tubulações recomendamos com o intuito de confirmar a presença destes corpos enterrados a realização de outras pequenas escavações nos locais onde os perfis demonstraram existir interferências. Já para maior compreensão das zonas de atenuação identificadas é recomendável o monitoramento da área investigada através de poços de monitoramento, assim como a realização de outros levantamentos futuros com o propósito de uma análise comparativa, temporal e espacial da área.

\section{Agradecimentos}

Agradecemos à Mineradora Fazenda Brasileiro pelo apoio logístico e informações de campo, ao LAGEP/CPGG pela infra-estrutura disponibilizada e à SBGf pela bolsa de estudos ao autor Leonardo.

\section{Referências}

Beres, M. \& Haeni, F. P., 1991. Application of GroundPenetrating-Radar Methods in Hidrogeologic Studies. Ground Water, 29(3): 375-386.

Davis, J. L. \& Annan, A. P., 1989. Ground-penetrating radar for high-resolution mapping of soil and rock stratigraphy. Geophys. Prospect., 37: 531-551.

Reinhardt, M. C., 1988. Controles Lito-Estruturais da Mineralização Aurífera em Zona de Cisalhamento da Mina Fazenda Brasileiro, Bahia, Tese de mestrado, Universidade Federal da Bahia, Salvador, Brasil.

Teixeira, J. B. G., 1984. Geologia e Controles da Mineralização de Ouro da Fazenda Brasileiro, Serrinha (BA), Tese de mestrado, Universidade Federal da Bahia, Salvador, Brasil. 


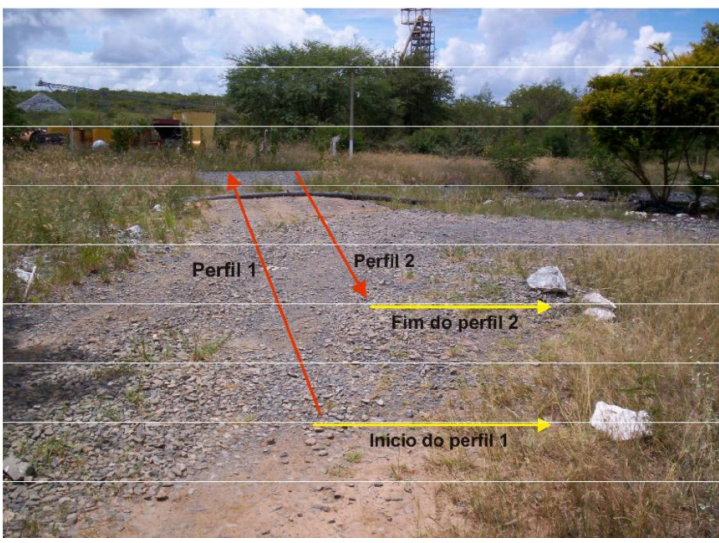

Figura 2-Trajetórias dos perfis 1 e 2 com a indicação dos pontos de saída e de chegada.

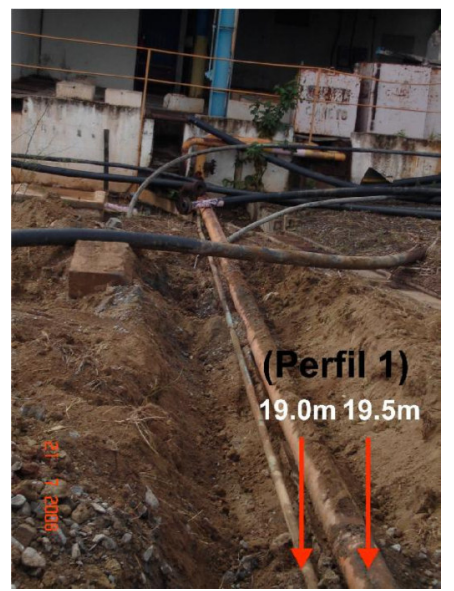

Figura 4 - Imagem mostrando duas tubulações e suas distâncias no perfil 1.

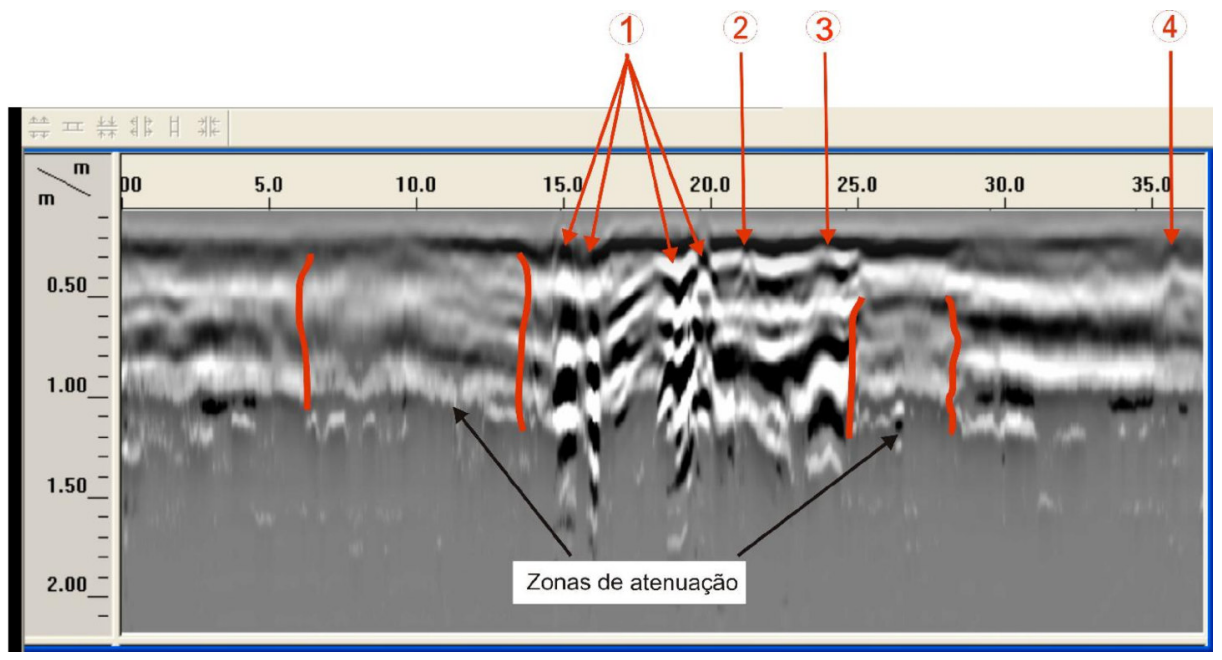

Figura 3 - Radargrama correspondente ao perfil 1.

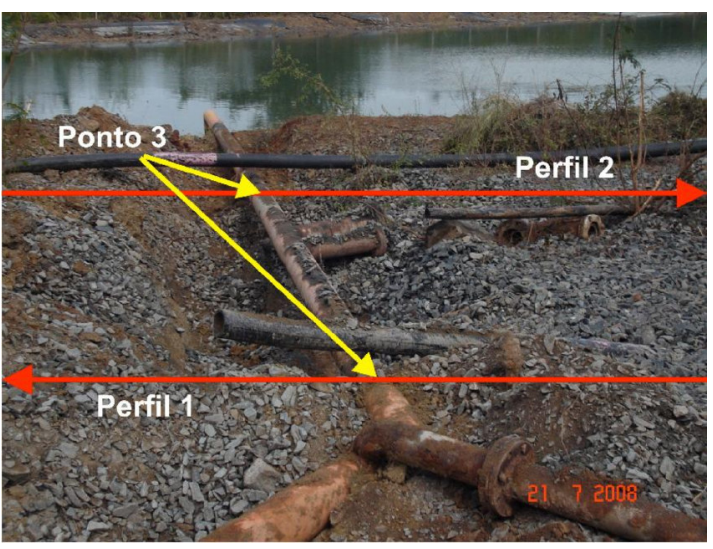

Figura 5 - Tubulação desenterrada correspondente ao ponto 3 dos perfis 1 e 2 .

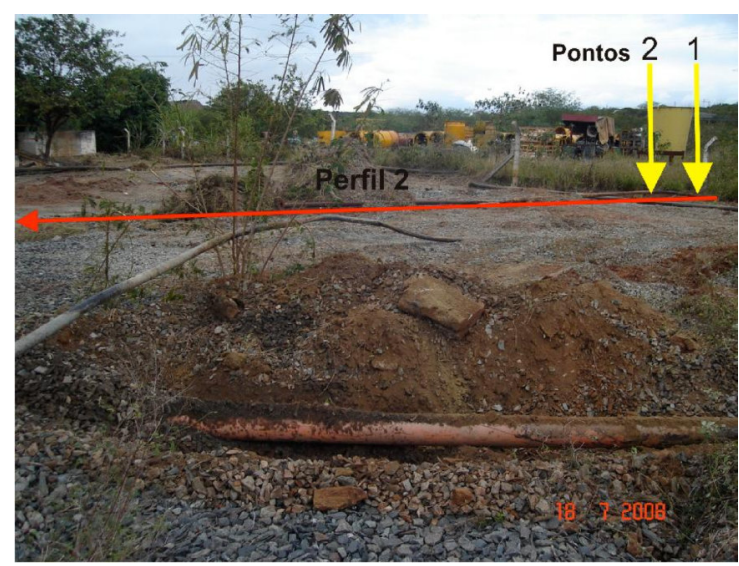

Figura 6-Duas tubulações correspondentes às interferências 1 e 2 do perfil 2 . 


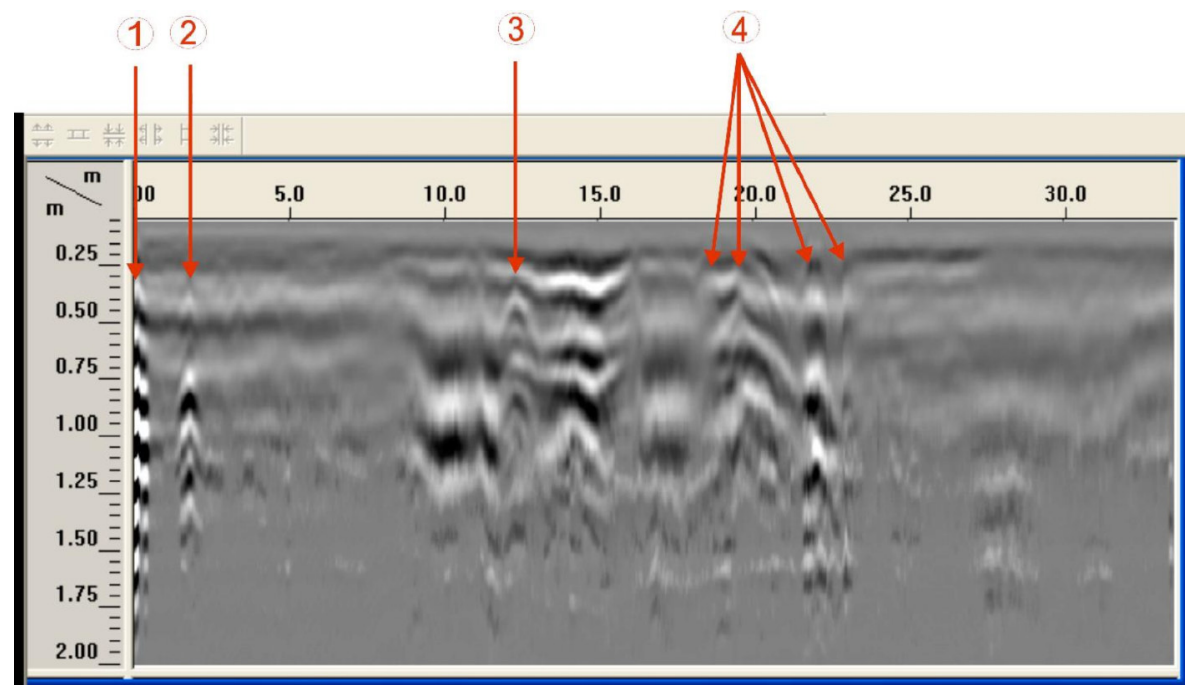

Figura 7 - Radargrama correspondente ao perfil 2.

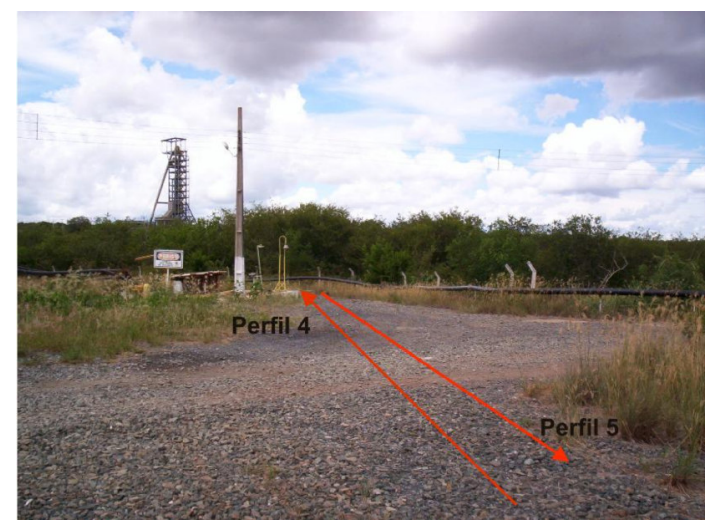

Figura 8-Representação das linhas de aquisição dos perfis 4 e 5 .

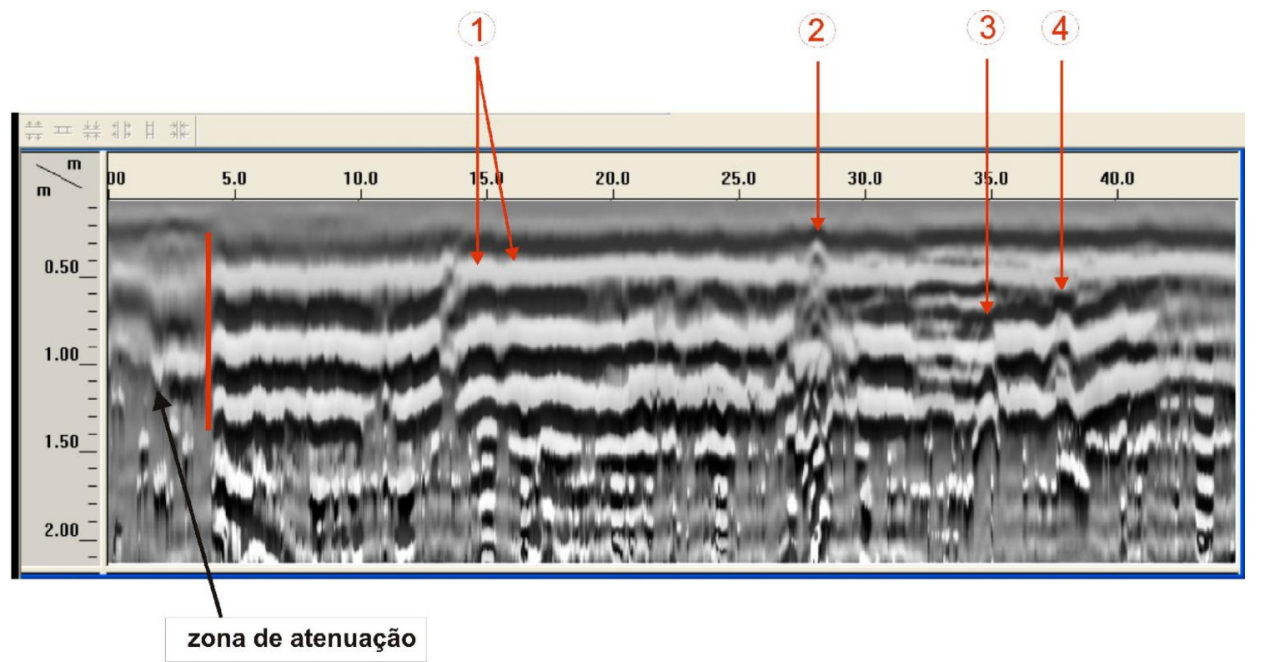

Figura 9 -Radargrama correspondente ao perfil 4.

III Simpósio Brasileiro da SBGf - Belém 2008 


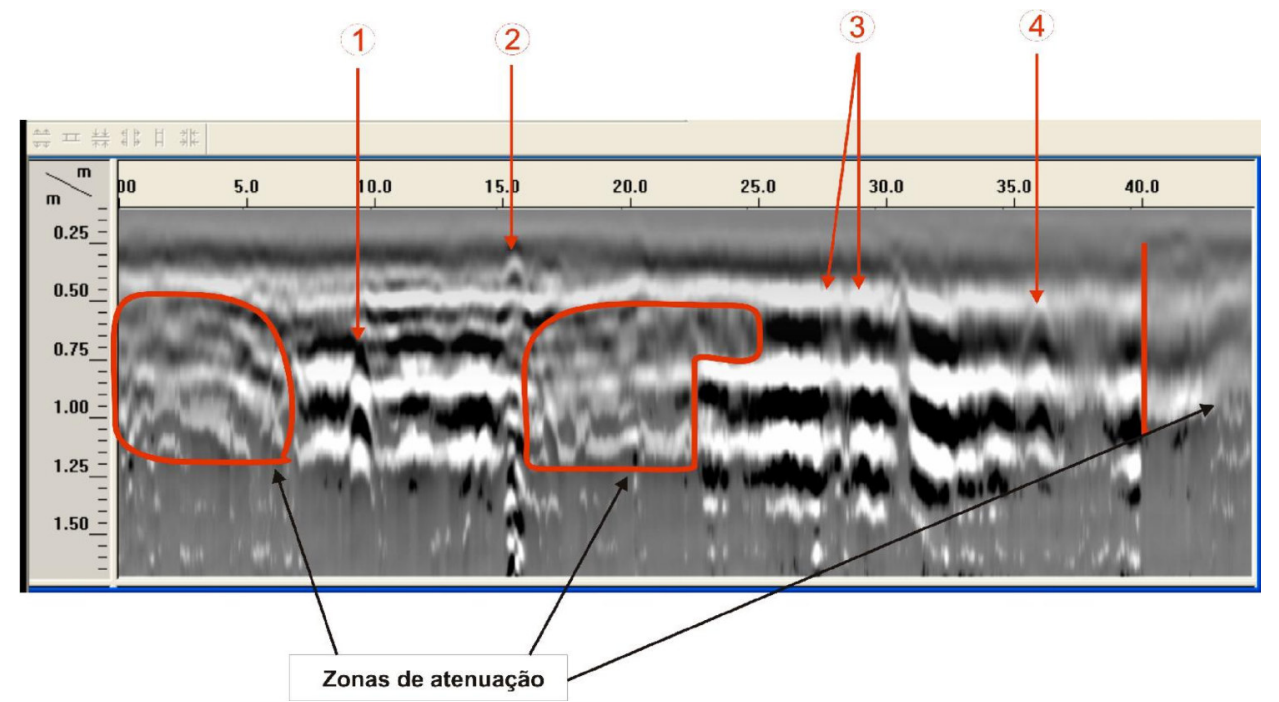

Figura 10 - Radargrama correspondente ao perfil 5.

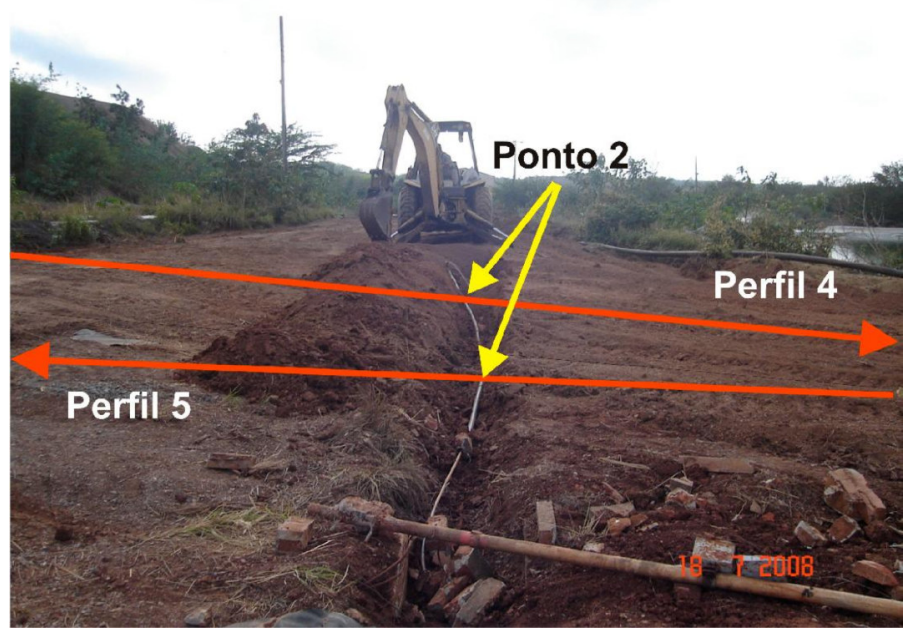

Figura 11 - Imagem mostrando a tubulação indicada como ponto 2 nos perfis 4 e 5 . 